\title{
Investigation and Analysis of the Inheritance Status of Tai Chi Culture in University Public Physical Education in Xinxiang
}

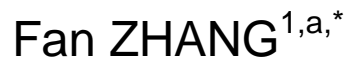 \\ ${ }^{1}$ Wushu Department, Chengdu Sport University, Chengdu, China \\ a752189467@qq.com
}

Keywords: Tai Chi, Culture, Education.

\begin{abstract}
In view of the concept of seeking scientific and healthy inheritance of Tai Chi, starting from the perspective of sociology research, using research methods such as questionnaires and literature data, revealing the current situation of inheritance of Tai Chi Culture in the college population. The study holds that Tai Chi, as one of the public physical education courses in colleges and universities, plays an irreplaceable role in helping students understand traditional culture and establish national self-confidence. Attention should be paid to its cultural and educational value in learning Tai Chi to strengthen college students' cognition of Chinese traditional culture and its influence themselves, and putting forward constructive suggestions from the perspective of development of Tai Chi cultural heritage.
\end{abstract}

\section{Introduction}

Tai Chi is a form of heritage which is formed and retained in the long historical river of the traditional culture. It is engraved with the cultural fingerprint of the Chinese nation, whose important role of identity, historical memory and theory construction of national culture is self-evident. Tai Chi is one of the carriers of national culture, which fuses and absorbs the essence of traditional culture, so cultural characteristic is the remarkable feature. As far as students' cognition of Tai Chi, It can no longer satisfy the cultural connotation, cultural charm and cultural value of Tai Chi when it is regarded as a kind of sports item. As we all know, the inheritance of Tai Chi is not only confined to the technical level, but also the inheritance of traditional virtues. Therefore, the cognition of Tai Chi of college students has a close relationship with the inheritance development of Tai Chi.

With the continuous integration of eastern and Western culture and the deepening of the educational reform in colleges and universities, the Tai Chi class has changed rapidly in teaching contents and methods. Even so, Tai Chi culture inheritance in colleges and universities still lags behind the development of Tai Chi sport in the form. The extensive development of Tai Chi cannot be separated from the "position" of school. But now we are facing a very grim reality which is not optimistic. Karate and Kendo from Japan, as well as Taekwondo from South Korea are very popular in China in recent years, and has gradually become a seemingly fashionable movement among the young people. By analyzing the above problems, it is not difficult to find its principle reason lies in Tai Chi teaching mode, which fails to really make students understand their deep culture. Though has been included in the curriculum of the school plan, however, the development of Tai Chi was gradually formalized, hollowed out and marginalized because of the neglect of the culture teaching[1]. Under this background, this study would analyze the impact and effect of Tai Chi education on contemporary college students' national spirit and personality in the five colleges and universities in Xinxiang city of Henan province, put forward some constructive 
suggestions and a new way to promote development of Tai Chi education in colleges and universities in Xinxiang City from the angle of development, so as to look forward to form a strong campus cultural atmosphere of Martial Arts in this area. It is of great significance to develop Martial Arts, to improve students' sense of national pride and to enhance students' physique.

\section{Investigation and Research of Impact of Tai Chi Culture Inheritance on College students' National Spirit and Personality}

Tai Chi culture is guided by Chinese traditional culture in theory, which guides and disciplines people's thought and spirit and ways of thinking [2]. As one of the boxing forms which is developing the best, the popularity of Tai Chi in colleges and universities is not ideal. Tai Chi not only has the characteristics of traditional culture, but also has its unique characteristics, therefore, it plays an irreplaceable role in people's education.

\section{Respondents' Basic Information}

The research object of this article are students from classes of 2014, 2015 and 2016 which provide Tai Chi courses in Henan Normal University, Henan Institute of Science and Technology, Xinxiang Medical University, Xinxiang college, Henan Mechanical and Electrical Engineering College. A total of 320 questionnaires were handed out, and 312 questionnaires were collected, with a collection rate of $97.5 \%$. Among which 306 questionnaires were valid, with an effective rate of $98 \%$.

\section{Investigation and Analysis of Tai Chi Culture Promoting College students' Cognition of Traditional Culture}

Tai Chi shows not only the Oriental body culture, but also contains the connotation of national spirit. From the perspective of cultural heritage, keep alive the traditional culture, strengthen the cultural memory of Chinese people, and enhance participants' recognition of traditional culture. From the perspective of the development of Tai Chi, its functional evolution will also be constantly civilized and develop with the increasing required population. The traditional culture embodies the incomparable inner driving force to improve students' interest in Martial Arts by understanding traditional culture and strengthening the teaching on the level of Tai Chi culture.

Table 1. Tai Chi Culture Promotes College Students' Cognition of Traditional Culture

\begin{tabular}{ccc}
\hline & Frequency(persons) & Percentage (\%) \\
\hline Totally No & 7 & 2 \\
A Little Bit & 31 & 10 \\
Almost Yes & 170 & 56 \\
Totally Yes & 98 & 32 \\
Total & 306 & 100 \\
\hline
\end{tabular}

It is not difficult to find from the statistics that the Tai Chi practice of most of students can promote the cognition of traditional culture, but in fact, after some practitioners have contacted Tai Chi, they think that it cannot promote the cognition of traditional culture but simply exercise. The different understanding of the problem suggests that the popularization on the level of culture of Tai Chi technology in the teaching system is still not enough. It needs to further breakthrough the single mode in teaching technology; mine the cultural connotation of Tai Chi technology, which is an important part of traditional culture penetration into Tai Chi teaching. It not only 
makes students acquire the traditional cultural knowledge in the process of technology learning, but also enhances the exploration spirit of traditional culture, and enriches the all-round development of body technology. In the pattern of cultural diversity, the cognition boundaries of traditional culture in groups of colleges and universities may gradually weaken. By practicing Tai Chi and learning Tai Chi culture, guide students to deeply cognize and highly understand the traditional culture, and enables students to show national self-confidence[3] and cultural consciousness through the "warrior" and "gentle" behavior of the college students.

\section{The Influence of the Inheritance of Tai Chi Enlightenment Function on the Personality of College Students}

Enlightenment is not only confined to the category of knowledge education, but also the long term of the educated practicing and being influenced by a certain field or a certain idea. That is to say, changes of values after thought is gradually immersed and habits have gradually changed. First of all, the acquisition and transmission of Tai Chi Culture a common phenomenon in the field of culture. It can transfer the knowledge, experience, social norms and other cultural achievements accumulated and formed by predecessors into own qualities of the educated, so as to enable him to get the recognition and affirmation of the community in the field of culture. To teach and train the educated by educators is a way of inheritance of Tai Chi Culture, which instructs and guides the educated to acquire deep cognition and perception of Tai Chi culture, and to reach a consensus with his own cognition. In this process, the inheritance of Tai Chi culture penetrates in a double dimensions from the body to the thinking, so that the inheritors can understand and inherit the core contents of Tai Chi culture from the essence.

Table 2. Effect on the Personality of the Educated of the Enlightenment Function of Tai Chi

\begin{tabular}{lcc}
\hline & Frequency (persons) & Percentage (\%) \\
\hline Comity behavior training & 92 & 30 \\
Enhance students' aesthetic taste & 130 & 42 \\
Guide students health values & 84 & 28 \\
Total & 306 & 100 \\
\hline
\end{tabular}

College education shows not only the theoretical level of teaching, but also comprehensive educational shaping process of the educated from body, skills, morality and personality. The survey shows the Tai Chi culture is the product of combination with traditional culture, prompting practitioners to self-constraint on his own behavior within the ethical constraints. As the boxing proverb says "Practice martial before practicing Martial Arts", to regularize the practitioners behavior is the first condition of practicing Martial Arts. The atmosphere created by Tai Chi is in the "static" state, which can weaken practitioner's impetuous behaviors, and can highlight the spirit of traditional culture quality.

\section{Conclusions}

Survey the enlightenment function of Tai Chi from the perspective of culture, deeply analyze and macroscopically examine modernity inheritance and continuation of Tai Chi culture. Analyze the influence Tai Chi culture receives from multi culture and the enlightenment function it displays in the groups of colleges and universities, it can be found that Tai Chi has formed Martial Arts culture inheritance which is different from 
the traditional significance to some extent. In the recessive education function of Tai Chi, guide the students to reveal the problem of value, which is to stimulate students' awareness and understanding of traditional culture, but also one of the characteristics of Tai Chi style. After investigation and analysis, colleges and universities that have opened Tai Chi courses know a little less about students' study on the level of culture. Tai Chi culture teaching has a significant impact on the personality of contemporary college students, but still need the guidance of teachers in teaching to strengthen students to understand the traditional culture, cultivate their cultural awareness of enthusiasm.

\section{References}

[1] Leif Korsbaek. Edward Burnett Tylor: Anahuac or Mexico and the Mexicans, Ancient and Modern. Cuicuilco, 2009, Vol.16 (46)

[2] George P. Murdock. Cultural Anthropology: An Abridged Revision of Man and His Works .Melville J. Herskovits. [J].American Anthropologist, 1955, Vol.57 (6)

[3] Fei Xiaotong. Fei Xiaotong National Research Anthology [M]. National Press. 1998. 